\title{
Assessing Instructional Confidence of Secondary Health Educators in Illinois: Implications for Curricular and Policy Development
}

\author{
Charles P Holmes ${ }^{1,2, *}$ \\ ${ }^{1}$ Community Health, College of Applied Health Sciences, University of Illinois, Urbana-Champaign, Illinois, U.S.A. \\ ${ }^{2}$ Healthcare Management, University College, University of Denver, Denver, Colorado, U.S.A. \\ *Correspondence: Community Health, College of Applied Health Sciences, University of Illinois, Urbana- \\ Champaign, Illinois, U.S.A. E-mail: charles.holmes@du.edu
}

Received: June 20, 2018

doi:10.5430/jct.v7n2p120
Accepted: October 11, 2018 Online Published: November 18, 2018

URL: https://doi.org/10.5430/jct.v7n2p120

\begin{abstract}
To assess the relationship between the training/preparation of physical education teachers and their perceived instructional confidence levels across major topic areas established by the Illinois State Board of Education as critical content areas. In total, 283 individuals participated and were included in the data analysis. The participants surveyed were currently enrolled or recently graduated from physical education or kinesiology departments at (1.) the University of Illinois at Urbana-Champaign, (2.) Illinois State University, and (3.) Eastern Illinois University. Data were collected via in-person and email surveys using the HECS 18 item survey instrument. Analysis demonstrated a statistically significant difference exists between the perceived instructional confidence of current students and recent graduates regarding major health topic areas. Further work with this population is required to determine if the results seen in the state of Illinois are consistent. The next proposed sample area will be the state of Colorado and its three main Universities (University of Colorado, Colorado State University, Metropolitan State University of Denver) and their health and physical educators (HPE).
\end{abstract}

Keywords: college curriculum, physical education, health education, confidence

\section{Introduction}

Based on recent Youth Risk Behavioral Surveillance Survey (YRBSS) data and CDC projections, it is believed that children born on or after the year 2000 have a 1 in 3 chance of becoming overweight or obese in their lifetime (Centers for Disease Control [CDC], 2017). Compared with 1990, more than double the number of adolescents are overweight and nearly triple the number of teenagers. Without multiple levels of intervention, the quality of life and life expectancy in the United States will decrease in the coming generations CDC, 2018; Peterson, 2005; I.S.B.E. 2016). The reason for the shortened lifespan of young adults and the growing number of health issues affecting them is a topic that is often debated among health professionals. Many researchers believe that the ever-changing landscape of health education may be a sizable contributor to these health disparities (Castro, 2009; Porter, McGrath, \& Costello, 2008).

A recent development within health education over the years is that, due to budget constraints, the individuals in charge of providing K-12 health information are primarily trained as physical education instructors (Wilson, 2001, Dennis, McKenzie, and Chen, 2012; Manross, 2015). While on the surface this may not appear to be a significant issue, most parents and students do not realize that health educators have different curricular standards from county to county and from state to state (Schulte, 2008; Snyder, 2005). These variations can make adequate preparation of future instructors all the more difficult. What is also a concern is that for more than a century the United States of America has been operating physical and health education courses without any national standards or mandatory curricula (Education Portal, 2018; Gaudreault and Woods, 2012; NASPE, 2013).

At nearly all major four-year universities, those individuals interested in becoming health educators typically need only to take introductory level courses in health education to meet state health endorsement standards to teach health along with their chosen discipline. The particular courses recommended for certification at major four-year institutions are typically the lowest course levels in the health education sequence and are typically designed for 
freshmen in their first semesters of collegiate work (I.S.B.E., 2018; Manross, 2015; UK College of Education, 2018; University of Illinois, 2018)).

The concern with this trend is that future instructors trained in physical education or other disciplines are not required to have exposure to any particular health topics in a depth that would be deemed significant by health education literature or health education experts (Jones, 2011; M. Simon, 2010). Most health education experts agree, if an individual desires to teach health in addition to another course, they should be required to have a solid background in health education so that they feel some mastery of the subject matter and can enter the classroom with greater confidence at all K-12 levels (Castro, 2009; Davidson, 2008; Journal of Physical Education, Recreation \& Dance [JOPERD], 2012).

Using health education as the focus, this study sought to assess the relationship between the training/preparation of physical education teachers and their confidence in delivering health education information to high school students. High school students (Grades 9-12) were chosen because at this level the students are typically exposed to a more complete picture of adult health habits and behaviors (CDC, 2017).

This study is of interest because no prior research had been conducted to assess the quality and/or ability of physical education instructors from the perspective of health education. While curricular satisfaction and teacher preparedness are somewhat common areas for research, the focus on the modern transition of physical educators to become health educators and their confidence levels regarding this transition was an uncharted area of inquiry.

\section{Method}

The primary goal of this study was to determine the confidence levels of upperclass students in the process of becoming physical educators and health educators and comparing them with the confidence levels of recent graduates of the same institutions, who are currently employed as health and physical educators (HPE). It should be noted that confidence levels were measured via survey and that questions assessing this confidence cover broad topic areas familiar to all health educators. Specifically, instructional confidence was measured on the topics of physical fitness, obesity prevention methods, nutrition, illicit drug use, and human sexuality. These topic areas were chosen based on the yearly YRBSS, the CDC health behavior surveys, and the Illinois Department of Education health endorsement standards criteria.

\subsection{Participants}

For this study upperclass (Junior or Senior standing) adult males and females enrolled in Kinesiology/Physical Education at one of the three study institutions were surveyed (The University of Illinois at Urbana-Champaign, Illinois State University, and Eastern Illinois University). All data for upperclassmen was collected during class time, and the classes chosen at the three institutions were selected in conjunction with the department heads and faculty members teaching those courses. Ultimately, the decision was made to administer the survey to the students enrolled in courses for students planning to pursue careers as K-12 HPE instructors or courses that assist students in earning the health endorsement from the Illinois State Board of Education.

In total 162 surveys from upperclassmen across all three study institutions were collected and analyzed.

Graduates of the past two years from these institutions were the second group of interest for this study. However, this group provided the added complication of communication and tracking. With the aid of the department heads, an email list for each school was provided for recent graduates who majored in physical education. The initial goal was to have only emails of graduates who achieved state health endorsement provided, but due to unforeseen complications with alumni associations, all graduates of the three physical education programs were provided. In order to qualify for participation in this study, all participants were required to be currently employed at a secondary school or high school at the time of survey admission and must be teaching both physical education and health education.

In total 120 surveys from working graduates across all three study institutions were collected and analyzed.

\subsection{Instrument}

In order to determine if there was a difference between current students and recent graduates' confidence levels, the Health Education Confidence Survey (HECS) was constructed (see Form A \& Form B). The HECS was developed by the lead author using a combination of existing and proven survey instruments from the Illinois State Board of Education (ISBE), the Youth Risk Behavioral Surveillance Survey (YRBSS), surveys constructed by Snyder (2005), and the 35 competencies developed by the National Commission for Health Education Credentialing (NCHEC). 
The HECS consists of 18 questions and on average took no student more than 10 minutes to complete. Questions 1-6 were modified from Snyder's (2005) survey assessing satisfaction and overall confidence regarding current health educators in Indiana, their curricula, and their level of professional support. Questions 7-11 consist of items aimed at assessing the individuals' perceived instructional confidence level for the given topic area. The questions were derived from a combination of the following: (1) the YRBSS and their results indicating the areas of most need for adolescent and young adult issues, (2) the ISBE secondary level health education endorsement standards, and (3) the NCHEC core competencies. Utilizing these three accepted sources, it was hoped to assess the participants' confidence in developing a lecture of the listed topic areas to high school level students. The listed objectives underneath each of the questions were displayed to remind the participants of what was expected under each indicated topic area. Finally, questions 12-18 collect anonymous demographic information to allow for a deeper analysis.

While numerous studies have demonstrated the reliability and validity of the YRBSS and BRFSS, the HECS is entirely new, and all of the questions have been modified to suit this study (Furlong, Bates, Sharkey, and Smith, 2004; Nelson, Holtzman, Bolen, Stanwyck, \& Mack, 2001). Efforts were made to assess the reliability and validity of the HECS. Specifically, the reliability of the HECS was examined through a test - retest analysis. This test - retest took place in the fall semester and consisted of eleven individuals from the projected participant pool taking the survey in a timed interval of 5 minutes, waiting approximately 50 minutes, and then taking the survey again. Upon completion, it was found that their answers were statistically consistent $(\mathrm{R}=.896)$ with their first test and that the survey was deemed reliable for this preliminary study regarding instructional confidence.

In terms of validity, experts in the fields of health education, physical education, and survey methodology were asked to assess the content validity of the HECS. These experts examined each item on the survey to determine readability, soundness, and accuracy of the material, and the appropriateness of scale and scope. All experts consulted stated the HECS was a sound instrument for the proposed study. The HECS contains 18 items in total with 12 using a Likert-type scale (1-5) and the remaining 6 using dichotomous responses or ordinal data (e.g., yes - no).

Q1-Q6 assessed the confidence of each individual that their curricular program was meeting their expectations, as well as, the professional standards developed by the state. These measures cover curriculum, content exposure, coursework depth, and job preparation. All questions, except for Q1 (Health Endorsement), used a Likert-type scale ranging from $1=$ Strongly Disagree to $5=$ Strongly Agree. For Q1 Are you working towards a health teaching endorsement the responses choices were Yes - No - Unsure. For the five questions that assessed confidence, a Likert-type scale was used to allow the participant to indicate a range of perceived instructional confidence for the given topic areas. The measures obtained from Q7-Q11 of the HECS covered the following topic areas; Physical Fitness, Obesity Prevention, Nutrition, Licit \& Illicit Drug Use, and Human Sexuality. Each confidence question was worded as follows: Based on training from my Health Endorsement coursework, I would feel confident teaching a lesson (Grades 9-12) regarding (insert specific topic area). Participants response choices ranged from $1=$ Strongly Disagree to $5=$ Strongly Agree, meaning lower values represented a lower feeling/sense of confidence for disseminating information for the given topic area and higher values represented a higher level of perceived confidence regarding the specific topic area. Q12-Q18 collected demographic information regarding the participants' gender, anticipated or achieved graduation date, major, and professional organization involvement. It should be noted that on the recent graduate's survey there was an additional question added to determine if the survey participant was working in an abstinence-only school district (see Form B).

\subsection{Procedures}

Survey administration took place prior to the end of the fall and spring semesters. The three college sites were chosen both for their proximity to one another and for the size of their physical education programs in relation to other nearby institutions. Further, as required by IRB protocol, all participants were provided with a consent form, stating that the survey was entirely optional, completely anonymous, and that participation with this study would not affect their educational or professional status at any point. Those individuals who chose to provide consent were asked to complete the survey instrument.

Since upperclassmen surveys were given firsthand by the lead author, the above methodology was carried out consistently at each testing site. However, for the recent graduates, surveying in person was not possible, so those individuals were contacted via email. The email addresses for recent graduates were obtained from department heads at all three institutions. Again, in keeping with IRB protocol, all potential participants were emailed a consent form explaining the purpose of the study, that they would remain anonymous, and their participation would in no way affect their professional status or employment either now or in the future. Upon receiving digital confirmation of 
their consent, the survey instrument was emailed to the participants with the caveat of a 24-hour return time. Ideally, the acceptance and return of the survey instrument would have been the same predetermined time used for the currently enrolled students, but due to varying schedules of professionals, this was not possible. Confidentiality of recent graduates was assured through the deletion of all of the contacts information following survey collection and data analysis.

\section{Results and Discussion}

Out of a possible 35 upperclassmen health endorsement seeking physical education (HPE) students at the University of Illinois, 33 participated, resulting in a 94.3\% return. The courses surveyed at Illinois State University comprised $100 \%$ of the upperclassmen HPE students, of which 53 or $82.8 \%$ participated, and at Eastern Illinois University HPE students were surveyed in courses, which again allowed for $100 \%$ of the study population to be eligible. Out of a possible 82 students enrolled in HPE coursework at EIU, 76 (or 92.6\%) participated.

This first subsection of the survey focused on curricular satisfaction and/or preparedness to determine if any findings of significance exist. An analysis of Q2 (Overall Curricular Satisfaction) revealed that current students $(\mathrm{N}=163)$ had an above average response $(M=3.987, S D=.947)$ which was statistically significant $(p=.0037)$ when compared to recent graduates $(\mathrm{N}=120)(M=3.643, S D=1.04)$ with the greatest university mean separation found between current ISU and EIU students $(p=.0258)$. In examining Q3 (Health Endorsement Satisfaction), no significant difference could be found between current students and recent graduates. Q4 (Future Employment), however, did result in a statistically significant difference between current students $(M=3.653, S D=.953)$ and recent graduates $(M=4.042$, $S D=.844)$ which resulted in $(p=.0004)$.

Q5 (Continuing Education) was found to be statistically different between current students and recent graduates $(p$ $<.0001)$. Current students indicated a much higher perceived support level $(M=3.809, S D=.906)$ versus recent graduates who indicated a perceived support as $(M=2.508, S D=.996)$. In Q6 (Recommend Program) both current students and recent graduates of their programs indicated above average means of $(M=4.18, S D=.957)$ and $(M=$ $4.06, S D=.807)$, indicating that the respondents do believe their programs are appropriate for those desiring to teach physical education in addition to health education at the 9-12 level.

For Q12 (Coursework Depth) it was found that the responses between the two groups were significantly different $(p$ $=.0065$ ). This finding may be an anomaly when compared to the responses from Q3, which asked participants to indicate how well they felt the health education coursework they had taken had prepared them for teaching health education at the 9-12 levels. Within this question was an additional significant finding comparing the mean responses of recent UIUC graduates $(M=2.619, S D=.740)$ and recent EIU graduates $(M=3.621, S D=.933, p<.0001)$ which were found to be significantly different. The final topical analysis occurred on Q13 (More Coursework Needed) which found that the current students indicated mean of $(\mathrm{M}=3.043, \mathrm{SD}=1.09)$ was significantly higher than the mean of recent graduates $(\mathrm{M}=2.483, \mathrm{SD}=1.21, p<.0001)$ indicating current students believe more coursework should be required during undergraduate training.

To test the consistency of the responses between current students and recent graduates for variance, a Levene's $t$-test was conducted on all of the instructional confidence questions. Based on the findings below, the null hypothesis could be rejected that either pre-service or in-service health instructors would indicate inconsistent levels of instructional confidence. Below are the results of the analyses:

\begin{tabular}{ll}
\hline \multicolumn{2}{c}{ Levene's $t$-Test for Homogeneity } \\
\hline Q7 $=p=.3021$ & Q10 $=p=.0192$ \\
Q8 $=p=.8084$ & Q11 $=p=.9741$ \\
Q9 $=p=.3459$ & \\
\hline
\end{tabular}

The Levene test confirmed that variance is not a significant factor across the tested sample for the questions designed to assess instructional confidence. Using these results, we then looked to the second research question to ultimately find out if the primary hypothesis of this study was achieved.

A two-way ANOVA was the primary test conducted due to the variable of interest, which was perceived instructional confidence across the two factors; universities (x3) and student status (x2). In addition, an unequal means - equal variance T-Test was used to support/reject the ANOVA findings, as well as to provide an additional test of the main hypothesis which found that pre-service and in-service physical educators do in fact have instructional confidence levels that were found to be statistically different and lacking in variation $(p<.0001)$. 
Below are the results of the two-way ANOVA with pre-service/in-service status being tested and a $t$-test comparing the means of pre-service and in-service physical educators (see Table $1-5$ and Table 11-12):

Q7-Q11. (F'<.0001) Satterthwaite $t$-test $(p<.0001)$

Q7. (Confidence in teaching Physical Education).........Two-Way ANOVA $(p=.6788)$

Q8. (Confidence in teaching Obesity Prevention)..........Two-Way ANOVA $(p<.0001)$

Q9. (Confidence in teaching Nutrition Education)......... Two-Way ANOVA $(p<.0001)$

Q10. (Confidence in teaching Drug Prevention)............Two-Way ANOVA $(p<.0001)$

Q11. (Confidence in teaching Human Sexuality)...........Two-Way ANOVA $(p<.0001)$

Table 1. Two-Way ANOVA with Interaction for University and Student Status Dependent Variable Question 7: Confidence Teaching Physical Fitness

\begin{tabular}{|c|c|c|c|c|c|}
\hline Source & DF & Sum of Squares & Mean Square & F Value & $\operatorname{Pr}>F$ \\
\hline Model & 5 & 6.2032592 & 1.2406518 & 1.65 & 0.1470 \\
\hline Error & 277 & 208.3126418 & 0.7520312 & & \\
\hline Corrected Total & 282 & 214.5159011 & & & \\
\hline R-Square & \multicolumn{2}{|c|}{ Coeff Var } & Root MSE & \multicolumn{2}{|c|}{ Question 7 Mean } \\
\hline 0.028917 & \multicolumn{2}{|r|}{20.78043} & 0.867197 & \multicolumn{2}{|c|}{4.173145} \\
\hline Source & DF & Type I SS & Mean Square & F Value & $\operatorname{Pr}>F$ \\
\hline University & 2 & 3.36646403 & 1.68323202 & 2.24 & 0.1086 \\
\hline Student Status & 1 & 0.82511075 & 0.82511075 & 1.10 & 0.2958 \\
\hline Universit $^{\wedge}$ Student Status & 2 & 2.01168443 & 1.00584222 & 1.34 & 0.2642 \\
\hline Source & $\mathrm{DF}$ & Type III SS & Mean Square & F Value & $\operatorname{Pr}>F$ \\
\hline University & 2 & 3.84501480 & 1.92250740 & 2.56 & 0.0794 \\
\hline Student Status & 1 & 0.12919178 & 0.12919178 & 0.17 & 0.6788 \\
\hline Universit ${ }^{\wedge}$ Student Status & 2 & 2.01168443 & 1.00584222 & 1.34 & 0.2642 \\
\hline
\end{tabular}

Notes:

* University = University of Illinois + Illinois State University + Eastern Illinois University

** Students Status $=$ Current Students + Recent Graduates

*** Universit ${ }^{\wedge}$ Student_St $=$ University + Student Status

Table 2. Two-Way ANOVA with Interaction for University and Student Status Dependent Variable Question 8: Confidence Teaching Obesity Prevention

\begin{tabular}{lccccc}
\hline Source & DF & Sum of Squares & Mean Square & F Value & Pr $>$ F \\
\hline Model & 5 & 55.5347823 & 11.1069565 & 14.15 & $<.0001$ \\
Error & 277 & 217.3839456 & 0.7847796 & & \\
Corrected Total & 282 & 272.9187279 & & & \\
\hline \multicolumn{1}{c}{ R-Square } & & Coeff Var & Root MSE & \multicolumn{2}{c}{ Question 8 Mean } \\
\hline \multicolumn{1}{c}{0.203485} & & 23.29958 & 0.885878 & \multicolumn{2}{c}{3.802120} \\
\hline Source & DF & Type I SS & Mean Square & F Value & $\operatorname{Pr}>$ F \\
\hline University & 2 & 4.47769332 & 2.23884666 & 2.85 & 0.0594 \\
Student Status & 1 & 44.56596916 & 44.56596916 & 56.79 & $<.0001$ \\
Universit ${ }^{\wedge}$ Student Status & 2 & 6.49111983 & 3.24555991 & 4.14 & 0.0170 \\
\hline Source & DF & Type III SS & Mean Square & F Value & $\operatorname{Pr}>$ F \\
\hline University & 2 & 6.27311116 & 3.13655558 & 4.00 & 0.0194 \\
Student Status & 1 & 35.36532588 & 35.36532588 & 45.06 & $<.0001$ \\
Universit ${ }^{\wedge}$ Student Status & 2 & 6.49111983 & 3.24555991 & 4.14 & 0.0170 \\
\hline
\end{tabular}

Notes:

* University = University of Illinois + Illinois State University + Eastern Illinois University

** Students Status $=$ Current Students + Recent Graduates

*** Universit ${ }^{\wedge}$ Student_St $=$ University + Student Status 
Table 3. Two-Way ANOVA with Interaction for University and Student Status

Dependent Variable Question 9: Confidence Teaching Nutrition Information

\begin{tabular}{|c|c|c|c|c|c|}
\hline Source & $\mathrm{DF}$ & Sum of Squares & Mean Square & F Value & $\operatorname{Pr}>F$ \\
\hline Model & 5 & 78.3029348 & 15.6605870 & 20.50 & $<.0001$ \\
\hline Error & 277 & 211.5769238 & 0.7638156 & & \\
\hline Corrected Total & 282 & 289.8798587 & & & \\
\hline R-Square $\quad$ Coeff Var & \multicolumn{2}{|c|}{ Root MSE Quest } & 9 Mean & & \\
\hline 0.270122 & \multicolumn{2}{|c|}{0.873965} & 3.399293 & & \\
\hline Source & DF & Type I SS & Mean Square & F Value & $\operatorname{Pr}>F$ \\
\hline University & 2 & 4.05033668 & 2.02516834 & 2.65 & 0.0723 \\
\hline Student Status & 1 & 71.59200903 & 71.59200903 & 93.73 & $<.0001$ \\
\hline Universit $^{\wedge}$ Student Status & 2 & 2.66058913 & 1.33029457 & 1.74 & 0.1771 \\
\hline Source & $\mathrm{DF}$ & Type III SS & Mean Square & F Value & $\operatorname{Pr}>F$ \\
\hline University & 2 & 3.67579780 & 1.83789890 & 2.41 & 0.0920 \\
\hline Student Status & 1 & 52.56628324 & 52.56628324 & 68.82 & $<.0001$ \\
\hline Universit $^{\wedge}$ Student Status & 2 & 2.66058913 & 1.33029457 & 1.74 & 0.1771 \\
\hline
\end{tabular}

Notes:

* University $=$ University of Illinois + Illinois State University + Eastern Illinois University

** Students Status $=$ Current Students + Recent Graduates

*** Universit ${ }^{\wedge}$ Student_St $=$ University + Student Status

Table 4. Two-Way ANOVA with Interaction for University and Student Status

Dependent Variable Question 10: Confidence Teaching Drug Prevention

\begin{tabular}{|c|c|c|c|c|c|c|}
\hline Source & DF & \multicolumn{2}{|c|}{ Sum of Squares } & Mean Square & F Value & $\operatorname{Pr}>F$ \\
\hline Model & 5 & \multicolumn{2}{|c|}{141.3532733} & 28.2706547 & 35.66 & \multirow[t]{3}{*}{$<.0001$} \\
\hline Error & 277 & \multicolumn{2}{|c|}{219.5937232} & 0.7927571 & & \\
\hline Corrected Total & 282 & \multicolumn{2}{|c|}{360.9469965} & & & \\
\hline R-Square Coeff Var & \multicolumn{2}{|c|}{ Root MSE } & \multicolumn{2}{|c|}{ Question 10 Mean } & & \\
\hline 0.391618 & \multicolumn{2}{|c|}{0.890369} & \multicolumn{2}{|c|}{3.279152} & & \\
\hline Source & & DF & Type I SS & Mean Square & F Value & $\operatorname{Pr}>F$ \\
\hline University & & 2 & 6.7068522 & 3.3534261 & 4.23 & 0.0155 \\
\hline Student Status & & 1 & 125.9277632 & 125.9277632 & 158.85 & $<.0001$ \\
\hline Universit $^{\wedge}$ Student Status & & 2 & 8.7186579 & 4.3593289 & 5.50 & 0.0046 \\
\hline Source & & DF & Type III SS & Mean Square & F Value & $\operatorname{Pr}>\mathrm{F}$ \\
\hline University & & 2 & 8.36865859 & 4.18432929 & 5.28 & 0.0056 \\
\hline Student Status & & 1 & 98.99838270 & 98.99838270 & 124.88 & $<.0001$ \\
\hline Universit $^{\wedge}$ Student Status & & 2 & 8.71865787 & 4.35932894 & 5.50 & 0.0046 \\
\hline
\end{tabular}

Notes:

* University $=$ University of Illinois + Illinois State University + Eastern Illinois University

** Students Status $=$ Current Students + Recent Graduates

$* * *$ Universit ${ }^{\wedge}$ Student_St $=$ University + Student Status 
Table 5. Two-Way ANOVA with Interaction for University and Student Status Dependent Variable Question 11: Confidence Teaching Human Sexuality

\begin{tabular}{|c|c|c|c|c|c|c|}
\hline Source & DF & \multicolumn{2}{|c|}{ Sum of Squares } & Mean Square & F Value & $\operatorname{Pr}>F$ \\
\hline Model & 5 & & 550781 & 10.7710156 & 11.82 & $<.0001$ \\
\hline Error & 277 & 252 & 053460 & 0.9115716 & & \\
\hline Corrected Total & 282 & 306 & 604240 & & & \\
\hline R-Square Coeff Var & \multicolumn{2}{|c|}{ Root MSE } & \multicolumn{2}{|c|}{ Question 11 Mean } & & \\
\hline 26.99279 & 0.95 & 4763 & 3.53 & & & \\
\hline Source & & $\mathrm{DF}$ & Type I & Mean Square & F Value & $\operatorname{Pr}>F$ \\
\hline University & & 2 & 13.7105 & 6.85525784 & 7.52 & 0.0007 \\
\hline Student Status & & 1 & 24.87498 & 24.87498083 & 27.29 & $<.0001$ \\
\hline Universit $^{\wedge}$ Student Status & & 2 & 15.26958 & 7.63479078 & 8.38 & 0.0003 \\
\hline Source & & DF & Type III & Mean Square & F Value & $\operatorname{Pr}>F$ \\
\hline University & & 2 & 15.30505 & 7.65252717 & 8.39 & 0.0003 \\
\hline Student Status & & 1 & 16.16098 & 16.16098200 & 17.73 & $<.0001$ \\
\hline Universit^${ }^{\wedge}$ Student Status & & 2 & 15.26958 & 7.63479078 & 8.38 & 0.0003 \\
\hline
\end{tabular}

Notes:

* University $=$ University of Illinois + Illinois State University + Eastern Illinois University

** Students Status $=$ Current Students + Recent Graduates

*** Universit ${ }^{\wedge}$ Student_St $=$ University + Student Status

Table 6. Testing the Equality of Means for Current Students and Recent Graduates

Question 7: (Confidence Teaching Physical Fitness)

\begin{tabular}{|c|c|c|c|c|c|c|c|c|}
\hline Student Status & $\mathrm{N}$ & Mean & Std Dev & Std Err & Minimum & \multicolumn{2}{|c|}{ Maximum } & \\
\hline Current & 16 & 4.2209 & 0.8680 & 0.0680 & 1.0000 & \multicolumn{2}{|c|}{5.0000} & \\
\hline Recent & 12 & 4.1083 & 0.8773 & 0.0801 & 2.0000 & \multicolumn{2}{|c|}{5.0000} & \\
\hline $\operatorname{Diff}(1-2)$ & & 0.1125 & 0.8719 & 0.1049 & & & & \\
\hline Student Status & & Method & Mean & \multicolumn{2}{|c|}{ 95\% CL Mean } & Std Dev & $95 \% \mathrm{CI}$ & Std Dev \\
\hline Current & & & 4.2209 & 4.0866 & 4.3551 & 0.8680 & 0.7829 & 0.9740 \\
\hline Recent & & & 4.1083 & 3.9498 & 4.2669 & 0.8773 & 0.7786 & 1.0049 \\
\hline Diff (1-2) & & \multirow{2}{*}{$\begin{array}{l}\text { Pooled } \\
\text { Satterthwaite }\end{array}$} & 0.1125 & -0.0939 & 0.3190 & 0.8719 & 0.8054 & 0.9505 \\
\hline $\operatorname{Diff}(1-2)$ & & & 0.1125 & -0.0944 & 0.3194 & & & \\
\hline Method & & Variances & DF & t Value & $\operatorname{Pr}>|t|$ & & & \\
\hline Pooled & & \multirow{2}{*}{$\begin{array}{c}\text { Equal } \\
\text { Unequal }\end{array}$} & 281 & 1.07 & 0.2842 & & & \\
\hline Satterthwaite & & & 255.02 & 1.07 & 0.2851 & & & \\
\hline \multicolumn{5}{|c|}{ Equality of Variances } & & & & \\
\hline Method & Num DF & Den DF & F Value & $\operatorname{Pr}>F$ & & & & \\
\hline Folded F & 119 & 162 & 1.02 & 0.8935 & & & & \\
\hline
\end{tabular}

Notes:

* If Folded F P-Value $>.05$ then must use Pooled or Equal Variance

** If Folded F P-Value $<.05$ then must use Satterthwaite or Unequal 
Table 7. Testing the Equality of Means for Current Students and Recent Graduates Question 8: (Confidence Teaching Obesity Prevention)

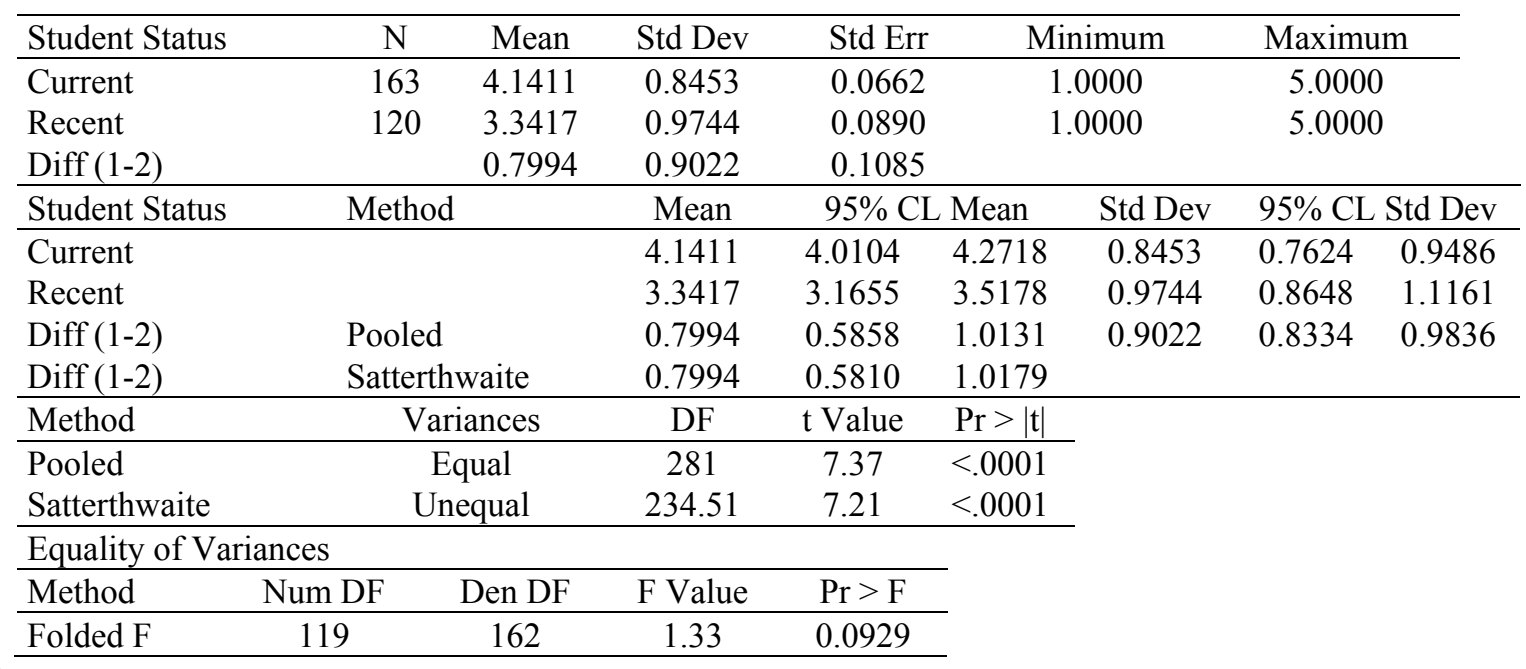

Notes:

* If Folded F P-Value $>.05$ then must use Pooled or Equal Variance

** If Folded F P-Value $<.05$ then must use Satterthwaite or Unequal

Table 8. Testing the Equality of Means for Current Students and Recent Graduates

Question 9: (Confidence Teaching Nutrition Information)

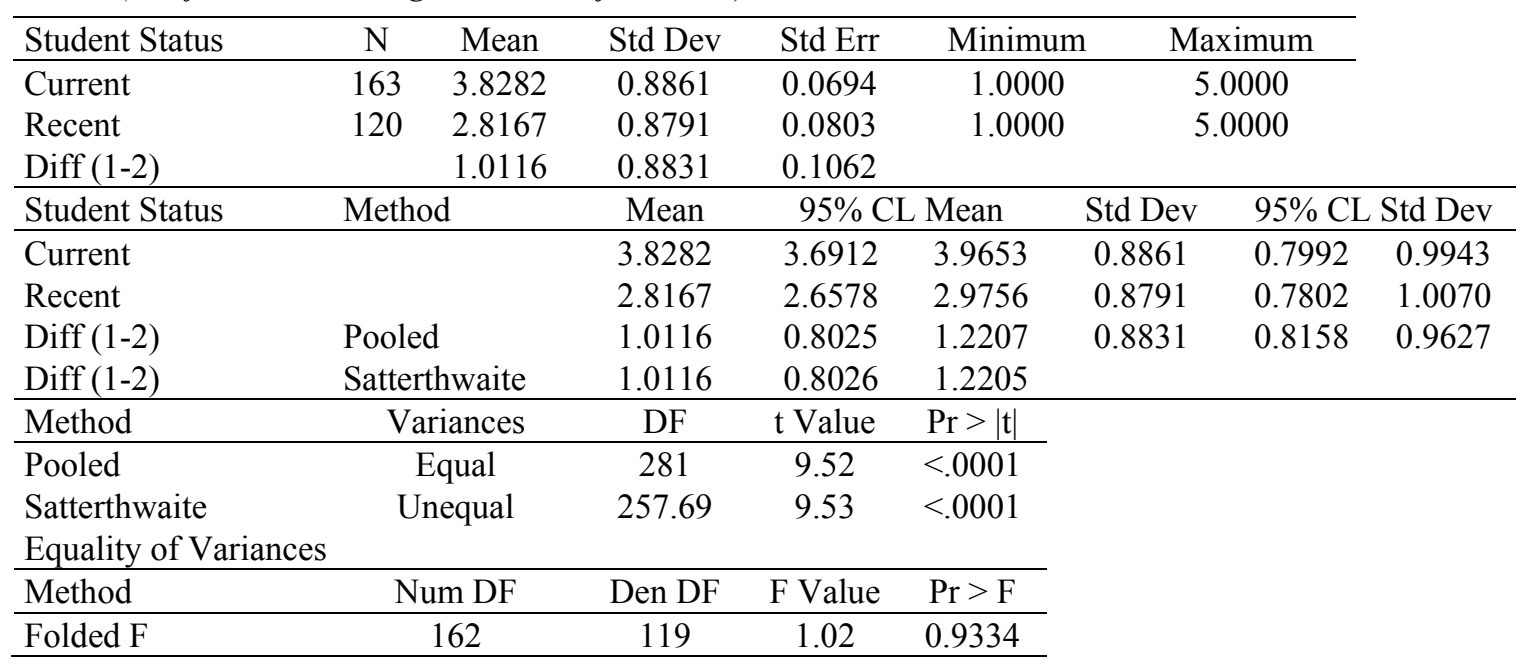

Notes:

* If Folded F P-Value $>.05$ then must use Pooled or Equal Variance

** If Folded F P-Value $<.05$ then must use Satterthwaite or Unequal 
Table 9. Testing the Equality of Means for Current Students and Recent Graduates Question 10: (Confidence Teaching Drug Prevention)

\begin{tabular}{|c|c|c|c|c|c|c|c|c|}
\hline Student Status & $\mathrm{N}$ & Mean & Std Dev & \multicolumn{2}{|c|}{ Std Err } & Minimum & \multicolumn{2}{|c|}{ Maximum } \\
\hline Current & 163 & 3.8466 & 0.9531 & \multicolumn{2}{|c|}{0.0747} & 1.0000 & \multicolumn{2}{|c|}{5.0000} \\
\hline Recent & 120 & 2.5083 & 0.8696 & \multicolumn{2}{|c|}{0.0794} & 1.0000 & \multicolumn{2}{|c|}{5.0000} \\
\hline $\operatorname{Diff}(1-2)$ & & 1.3383 & 0.9187 & \multicolumn{2}{|l|}{0.1105} & & \multirow{2}{*}{\multicolumn{2}{|c|}{ 95\% CL Std Dev }} \\
\hline Student Status & Method & & Mean & \multicolumn{2}{|c|}{ 95\% CL Mean } & Std Dev & & \\
\hline Current & & & 3.8466 & 3.6992 & 3.9940 & 0.9531 & 0.8597 & 1.0695 \\
\hline Recent & & & 2.5083 & 2.3511 & 2.6655 & 0.8696 & 0.7718 & 0.9961 \\
\hline Diff (1-2) & \multicolumn{2}{|l|}{ Pooled } & 1.3383 & 1.1208 & 1.5558 & 0.9187 & 0.8486 & 1.0015 \\
\hline $\operatorname{Diff}(1-2)$ & \multicolumn{2}{|c|}{ Satterthwaite } & 1.3383 & 1.1237 & 1.5528 & & & \\
\hline Method & \multicolumn{2}{|c|}{ Variances } & DF & t Value & $\operatorname{Pr}>|t|$ & & & \\
\hline Pooled & & 281 & 12.11 & $<.0001$ & & & \\
\hline Satterthwaite & \multicolumn{2}{|c|}{ Unequal } & 268.37 & 12.28 & $<.0001$ & & & \\
\hline \multicolumn{6}{|c|}{ Equality of Variances } & & & \\
\hline Method & Num DF & Den DF & F Value & & $r>F$ & & & \\
\hline Folded F & 162 & 119 & 1.20 & & 2902 & & & \\
\hline
\end{tabular}

Notes:

* If Folded F P-Value $>.05$ then must use Pooled or Equal Variance

** If Folded F P-Value $<.05$ then must use Satterthwaite or Unequal

Table 10. Testing the Equality of Means for Current Students and Recent Graduates

Question 11: (Confidence Teaching Human Sexuality)

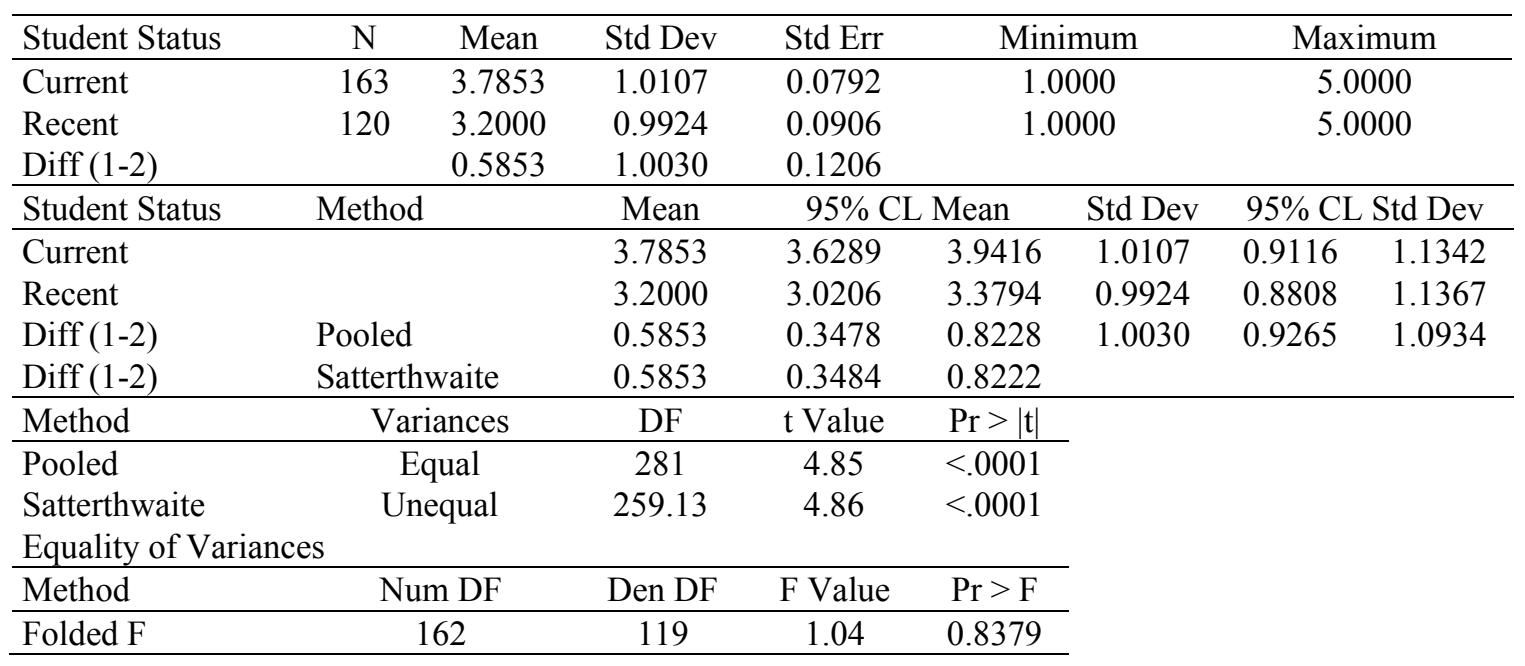

Notes:

* If Folded F P-Value $>.05$ then must use Pooled or Equal Variance

** If Folded F P-Value $<.05$ then must use Satterthwaite or Unequal 
Table 11. Scale Reliability for Question 7 - Question 11

Cronbach Coefficient Test

\begin{tabular}{lcccccc}
\hline Variable & $\mathrm{N}$ & Mean & Std Dev & Sum & Minimum & Maximum \\
\hline Question_7 & 283 & 4.17314 & 0.87218 & 1181 & 1.00000 & 5.00000 \\
Question_8 & 283 & 3.80212 & 0.98377 & 1076 & 1.00000 & 5.00000 \\
Question_9 & 283 & 3.39929 & 1.01388 & 962.00000 & 1.00000 & 5.00000 \\
Question_10 & 283 & 3.27915 & 1.13135 & 928.00000 & 1.00000 & 5.00000 \\
Question_11 & 283 & 3.53710 & 1.04230 & 1001 & 1.00000 & 5.00000 \\
\hline
\end{tabular}

Cronbach Coefficient Alpha

\begin{tabular}{ll} 
Variables & Alpha \\
\hline Raw & 0.783113 \\
Standardized & 0.779602
\end{tabular}

Cronbach Coefficient Alpha with Deleted Variable

\begin{tabular}{|c|c|c|c|c|}
\hline $\begin{array}{l}\text { Deleted } \\
\text { Variable }\end{array}$ & $\begin{array}{c}\text { Raw Variables } \\
\text { Correlation } \\
\text { with Total }\end{array}$ & Alpha & $\begin{array}{c}\text { Standardized } \\
\text { Correlation } \\
\text { with Total } \\
\end{array}$ & Alpha \\
\hline Question_7 & 0.372234 & 0.795743 & 0.374781 & 0.795979 \\
\hline Question_8 & 0.596666 & 0.730429 & 0.596292 & 0.724325 \\
\hline Question_9 & 0.633975 & 0.717150 & 0.626620 & 0.713855 \\
\hline Question_10 & 0.624753 & 0.719733 & 0.617056 & 0.717174 \\
\hline Question 11 & 0.570711 & 0.738645 & 0.565186 & 0.734896 \\
\hline
\end{tabular}

Notes:

$* \quad \geq .70$ considered acceptable

** $\quad$ Raw $=$ Based upon item correlation. The stronger the items are inter-related, the more likely the test is consistent *** Standardized $=$ Based upon item covariance. The higher the correlation coefficient the higher the covariance.

Table 12. Testing the Equality of Instructional Confidence Means for Current Students and Recent Graduates

\begin{tabular}{|c|c|c|c|c|c|c|c|c|}
\hline Student Status & $\mathrm{N}$ & Mean & Std Dev & Std Err & \multicolumn{2}{|c|}{ Minimum } & \multicolumn{2}{|c|}{ Maximum } \\
\hline Current & 163 & 3.9644 & 0.7490 & 0.0587 & \multicolumn{2}{|c|}{1.0000} & \multicolumn{2}{|c|}{5.0000} \\
\hline Recent & 120 & 3.1950 & 0.4388 & 0.0401 & \multicolumn{2}{|c|}{2.2000} & \multicolumn{2}{|c|}{4.2000} \\
\hline Diff (1-2) & & 0.7694 & 0.6364 & 0.0765 & & & & \\
\hline Student Status & Method & & Mean & \multicolumn{2}{|c|}{ 95\% CL Mean } & Std Dev & \multicolumn{2}{|c|}{ 95\% CL Std Dev } \\
\hline Current & & & 3.9644 & 3.8486 & 4.0803 & 0.7490 & 0.6755 & 0.8404 \\
\hline Recent & & & 3.1950 & 3.1157 & 3.2743 & 0.4388 & 0.3895 & 0.5027 \\
\hline Diff (1-2) & \multirow{2}{*}{\multicolumn{2}{|c|}{$\begin{array}{l}\text { Pooled } \\
\text { Satterthwaite }\end{array}$}} & 0.7694 & 0.6187 & 0.9201 & 0.6364 & 0.5878 & 0.6937 \\
\hline $\operatorname{Diff}(1-2)$ & & & 0.7694 & 0.6296 & 0.9093 & & & \\
\hline Method & Variances & DF & t Value & $\operatorname{Pr}>|t|$ & & & & \\
\hline Pooled & Equal & 281 & 10.05 & $<.0001$ & & & & \\
\hline Satterthwaite & Unequal & 268.76 & 10.83 & $<.0001$ & & & & \\
\hline \multicolumn{5}{|c|}{ Equality of Variances } & & & & \\
\hline Method & Num DF & Den DF & F Value & $\operatorname{Pr}>F$ & & & & \\
\hline Folded F & 162 & 119 & 2.91 & $<.0001$ & & & & \\
\hline
\end{tabular}

Notes:

* If Folded F P-Value $>.05$ then must use Pooled or Equal Variance

** If Folded F P-Value <.05 then must use Satterthwaite or Unequal

The results of the two-way ANOVA test were found to be consistent when compared with the same data undergoing a standardized $t$-test comparing Current Students to Recent Students. In addition, the Folded F Statistic, a label of sample variance used within $S A S$, means if the $\mathrm{F}$ statistic ( $\left.\mathrm{F}^{\prime}\right)$ is $>.05$, then the variance is equal and the Pooled $t$-test result is valid. If $\mathrm{F}^{\prime}$ is $<.05$ then the variance is unequal and the Satterthwaite $t$-test result is valid. The results of the analyses can be found below (see Tables 6-10): 


$$
\begin{array}{llll}
\text { Q7. } & \left(\mathrm{F}^{\prime}=.8935\right) \text { Pooled } t \text {-test }(p=.2842) & \text { Q10. } & \left(\mathrm{F}^{\prime}=.2902\right) \text { Pooled } t \text {-test }(p<.0001) \\
\text { Q8. } & \left(\mathrm{F}^{\prime}=.0929\right) \text { Pooled } t \text {-test }(p<.0001) & \text { Q11. } & \left(\mathrm{F}^{\prime}=.8379\right) \text { Pooled } t \text {-test }(p<.0001)
\end{array}
$$

Q9. $\quad\left(\mathrm{F}^{\prime}=.9334\right)$ Pooled $t$-test $(p<.0001)$

Additionally, those students who listed their major as K-12 education displayed the highest overall levels of instructional confidence across the selected health topics $(M=3.863, S D=1.02)$ and those who listed their majors as Coaching Administration displayed the lowest overall levels of instructional confidence across the selected health topics $(M=3.167, S D=1.50)$.

\section{Conclusion and Recommendations}

While the findings of this study cannot be generalized across the entire physical education population, or even the complete physical education population in Illinois, there is sufficient evidence to support the argument that students who are currently enrolled in pre-service physical education courses do have instructional confidence levels that are significantly different than their in-service physical education peers. The findings in this study also support previous studies conducted by Schulte (2008), Snyder (2005), Renn (2008), and Yingling (2000) that currently enrolled students, regardless of discipline, will display higher levels of confidence than their recently graduated peers.

As shown in the analysis of Q2 (Overall Curricular Satisfaction), current students had an above average mean response which was found to be significantly different when compared to recent graduates responses $(p=.0037)$. These findings also support the research of Schulte (2008) and Taylor (1990), who found that currently enrolled students displayed higher levels of satisfaction and confidence than their in-service counterparts. While the case for instructors teaching outside of their chosen discipline is uncommon in most fields, for K-12 physical education instructors it is becoming the norm (JOPERD, 2012; Sirna, Tinning, \& Rossi, 2010). With that knowledge and these preliminary findings, a case could be made for curricular revision that not only addresses the physical education pedagogy aspects, but also emphasizes the health education pedagogy aspects across the most current salient topics. Additionally, the ANOVA findings for Q7 should not be seen as an anomaly as the students and graduates being surveyed were primarily trained in physical education. With Q7 asking participants, "Based on my training from my Health Endorsement coursework, I would feel confident teaching a lesson (Grades 9-12) regarding physical fitness." It is expected that participants who are primarily trained as physical education instructors would feel the most confident with this subject matter, hence the reason why it was statistically non-significant in both tests.

While the topics chosen for this survey are the broadest and most commonly used in state and federal testing, there are many other areas of health education that were not addressed (bullying, environmental health, etc.), and it is likely that these topics will come to be of greater interest as the years progress. Instructors entering the classroom with a false sense of confidence in their teaching abilities may also help to explain the rise in social norms serving as a primary source of information for adolescents and young adults (Centers for Disease Control, 2009; Jones, 2011; Wright, 2007). However, this study and its findings should not be construed as anything more than preliminary. Further testing using the HECS will need to occur at other universities throughout the country to support these early findings.

\section{References}

Castro, A. (2009). Texas drops health education requirement. Houston Chronicle. Retrieved from http://www.chron.com/disp/story.mpl/metropolitan/6518304.html

Centers for Disease Control. (2017). National Trends in Risk Behavior. Retrieved from https://www.cdc.gov/healthyyouth/data/yrbs/pdf/trendsreport.pdf

Centers for Disease Control. (2018). Youth Risk Behavior Surveillance Survey Morbidity and Mortality Weekly Report. Atlanta, GA Retrieved from https://www.cdc.gov/mmwr/volumes/67/ss/ss6708a1.htm?s_cid=ss6708a1_w

Davidson, E. S. (2008). Perceived Continuing Education Needs and Job Relevance of Health Education Competencies among Health Education and Promotion Practitioners in College Health Settings. Journal of American College Health, 57(2), 197-209. https://doi.org/10.3200/JACH.57.2.197-210

Dennis, D., McKenzie, J.F., \& Chen, W.W. (2012). The Value of CHES (and now MCHES)?, American Journal of Health Education, 43(3), 130-131, https://doi.org/10.1080/19325037.2012.10599228

Education Portal. (2018). Education Requirements to Teach High School Courses. Retrieved from 
https://study.com/teach_high_school_classes.html

Furlong, M. J., Bates, M. P., Sharkey, J. D., \& Smith, D. C. (2004). The Accuracy of School and Non-School Risk Behaviors as Predictors of School Weapons Possession. Hauppauge, NY: Nova Science.

Gaudreault, K.L., \& Woods, A.M. (2012). The Effects of Achieved National Board for Professional Teaching Standards Certification on the Marginality of Physical Education Teachers. The Teacher Educator, 47(4), 283-301. https://doi.org/10.1080/08878730.2012.707760

I.S.B.E. (2016). Physical development and health performance descriptors. Springfield, IL. Retrieved from https://www.isbe.net/Documents/pdh_descriptor_6-12.pdf

I.S.B.E. (2018). Endorsement of teaching certificates. Retrieved from https://www.isbe.net/Pages/Subsequent-Teaching-Endorsements.aspx

Jones, P. (2011). Personal Communication, May 10, 2011.

JOPERD. (2012). Should physical educators be teaching health education in the public schools? Journal of Physical Education, Recreation \& Dance, 83(8), 54-54. https://doi.org/10.1080/07303084.2012.10598832

Manross, M. (2015). Becoming a Physical Education Teacher. Retrieved from https://www.pecentral.org/professional/becomingapeteacher.html

NASPE. (2013). National Standards for K-12 Physical Education. Retrieved from https://www.shapeamerica.org/standards/pe/

Nelson, D. E., Holtzman, D., Bolen, J., Stanwyck, C. A., \& Mack, K. A. (2001). Reliability and Validity of Measures from the Behavioral Risk Factor Surveillance System (BRFSS). Sozial und Praventivmedizin, 46(Suppl 1), S3-42. https://doi.org/10.1007/BF01318790

Peterson, Y. (2005). Family Therapy Treatment: Working with Obese Children and their Families with Small Steps and Realistic Goals. Acta Paediatrica, 94, 42-44. https://doi.org/10.1080/08035320510035573

Porter, J., McGrath, R., \& Costello, A. (2008). Development of an Evidence-Based Data Skills Curriculum for Public Health Professionals. American Journal of Health Education, 39(5), 314-317. https://doi.org/10.1080/19325037.2008.10599056

Renn, K. A., \& Jessup-Anger, E. R. (2008). Preparing New Professionals: Lessons for Graduate Preparation Programs from the National Study of New Professionals in Student Affairs. Journal of College Student Development, 49(4), 319-335. https://doi.org/10.1353/csd.0.0022

Schulte, L. E. (2008). The Development and Validation of a Teacher Preparation Program: Follow-Up Survey. Journal of Statistics Education, 16(3), 212-217. https://doi.org/10.1080/10691898.2008.11889576

Simon, M. (2010). DA to Teachers: New Sex Ed Course Could Get You Arrested. CNN. Retrieved from http://news.blogs.cnn.com/2010/04/07/da-to-teachers-new-sex-ed-course-could-get-you-arrested/

Sirna, K., Tinning, R., \& Rossi, T. (2010). Social Processes of Health and Physical Education Teachers' Identity Formation: Reproducing and Changing Culture. British Journal of Sociology of Education, 31(1), 71-84. https://doi.org/10.1080/01425690903385501

Snyder, S. L. (2005). An Assessment of Indiana Health Teachers' Needs and Capacity Related to Health Education. (Doctoral Dissertation), Purdue University. West Lafayette.

Taylor, G. R. (1990). A Follow-Up Study of the Former Students of the Undergraduate and Graduate Physical Education Programs at Texas A\&M University: 1985-1989. (Ed.D. Dissertation), Texas A\&M University. College Station, TX.

UK College of Education. (2018). Teacher Certification by State. Retrieved from https://education.uky.edu/accreditation/certification/states/

University of Illinois at Urbana-Champaign (UIUC). (2018). Health Education Course Offerings. Retrieved from http://catalog.illinois.edu/undergraduate/ahs/departments/ch-kines/ch/\#courseinventory

Wilson, C. C. (2001). Reminiscing on School Health. The Journal of School Health, 71(8), 376-377. https://doi.org/10.1111/j.1746-1561.2001.tb03520.x

Wright, L. S. (2007). A Norm Changing Approach to Drug Prevention. Journal of Drug Education, 37(2), 191-215. https://doi.org/10.2190/bm2m-5461-841t-0576 
Yingling, J. D. (2000). Perceptions of Undergraduate Alumni of a Private Liberal Arts University on the Adequacy of their Preparation in Kinesiology. (Ed.D. Dissertation), Texas A\&M University. College Station, TX.

\section{Forms}

Form A.

\section{Health Education Confidence Survey (HECS) Current Students}

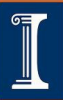

\section{University of Illinois at Urbana- Champaign}

\section{Directions:}

\section{Confidence Survey}

This survey is entirely optional. I would like your feedback on how well you believe your Kinesiology/Physical Education and/or Health Endorsement curriculum has prepared you for your work as a health educator. Please review and answer the following questions to the best of your ability.

Please rate your agreement with the following statements about your Kinesiology \& Physical Education program and/or Health Endorsement coursework

on a scale of 1 to 5 with 1 being strongly disagree and 5 being strongly agree:

\section{STATEMENT}

(Q1) Are you working towards a health education teaching endorsement

(Illinois State Board of Education Health Endorsement: A health endorsement is a statement appearing on a certificate that identifies the specific subject (in this case Health Education) and/or grade level that the certificate holder is authorized to teach based on specific health education coursework completed.)

Yes -- No - Not Sure

(Q2) My curriculum will expose me to all of the content (Physical Fitness, Obesity Prevention, Nutrition, Illicit Drug Use, Human Sexuality) I will need to teach health education effectively in grades 9-12

1-Strongly Disagree 2-Disagree 3-Neutral 4-Agree 5-Strongly Agree

(Q3) I feel confident that my Health Endorsement coursework will prepare me to teach health education (9-12) effectively

1-Strongly Disagree 2-Disagree 3-Neutral 4-Agree 5-Strongly Agree

(Q4) I have a good idea of what health education jobs I might be able to obtain when I complete the Kinesiology/Physical Education program 
1-Strongly Disagree 2 -Disagree 3-Neutral 4 -Agree 5 -Strongly Agree

(Q5) My undergraduate Kinesiology/Physical Education program has provided continuing education to me as a health educator

1 - Strongly Disagree 2 -Disagree 3 -Neutral 4 -Agree 5 -Strongly Agree

(Q6) For those interested in teaching school (K-12) health education,

I would recommend my Kinesiology/Physical Education program

1-Strongly Disagree 2 -Disagree 3 -Neutral 4 -Agree 5 -Strongly Agree

(Q7) Based on training from my Health Endorsement coursework,

I would feel confident teaching a lesson (Grades 9-12) regarding physical fitness

(Expected Learning Objectives: Apply Concepts Related To

Moving, Physical Fitness, and Foster Lifelong Physical Fitness Aspirations, etc.)

Pangrazi, R. (2009). Dynamic Physical Education for Elementary School Children (16 ${ }^{\text {th }}$ Edition).

1-Strongly Disagree 2-Disagree 3-Neutral 4-Agree 5-Strongly Agree

(Q8) Based on training from my Health Endorsement coursework,

I would feel confident teaching a lesson (Grades 9-12) regarding obesity prevention

(Expected Learning Objectives: Understanding the Health Outcomes of Overweight/Obesity at all Ages,

Explaining Safe Methods of Weight Management, etc.)

McKenzie, J. (2007). An Introduction to Community Health ( $6^{\text {th }}$ Edition).

1-Strongly Disagree 2 -Disagree 3-Neutral 4-Agree 5-Strongly Agree

(Q9) Based on training from my Health Endorsement coursework,

I would feel confident teaching a lesson (Grades 9-12) regarding nutrition

(Expected Learning Objectives: Explain Benefits of Healthy Foods vs. Less Healthy,

Develop Skills Needed For Informed Nutritional Choices, etc.)

Wardlaw, G. (2010). Contemporary Nutrition ( $7^{\text {th }}$ Edition).

1 -Strongly Disagree 2 -Disagree 3-Neutral 4-Agree 5 -Strongly Agree

(Q10) Based on training from my Health Endorsement coursework,

I would feel confident teaching a lesson (Grades 9-12) regarding the dangers of illicit drug use

(Expected Learning Objectives: Current Levels of Licit \& Illicit Drug Use, Development of Peer-Refusal Skills, Consequences of Drug Use Licit or Illicit, etc.)

Levinthal, C. (2010) Drugs, Behavior, and Modern Society (7 ${ }^{\text {th }}$ Edition).

1 - Strongly Disagree 2 -Disagree 3 -Neutral 4 -Agree 5 -Strongly Agree

(Q11) Based on training from my Health Endorsement coursework, I would feel confident teaching a lesson (Grades 9-12) regarding human sexuality

(Expected Learning Objectives: Explain how HIV and other STDs are Transmitted, Develop Peer-Refusal Skills, 
Explain Proper Contraception Usage, etc.)

Rathus, S. (2010). Human Sexuality in a World of Diversity ( $8^{\text {th }}$ Edition).

1-Strongly Disagree 2-Disagree 3-Neutral 4-Agree 5-Strongly Agree

(Q12) I feel that the health topics covered in my health education courses are presented in sufficient depth and detail to adequately prepare me to teach health education in (Grades 9-12) school settings

(See Above For Examples of Learning Objectives)

1 -Strongly Disagree 2-Disagree 3-Neutral 4-Agree 5-Strongly Agree

(Q13) I feel more health education courses should be required to earn a health teaching endorsement

1 - Strongly Disagree 2-Disagree 3-Neutral 4-Agree 5-Strongly Agree

Q14) Are you a member of one or more of the following organizations (SHES, APHA, AAHPERD, IAHPERD

$$
\text { Yes }- \text { No - Other (Please List } \rightarrow \text { ) }
$$

\section{(Q15) Your Gender}

Female - Male

(Q16) As a Kinesiology/Physical Education major, my primary focus is...

K-12 Teaching - Physical Education - Health Education - Biomechanics - Coaching/Administration - Undecided - Other

(Q17) What year do you plan to graduate

$2012-2013-2014-2015-2016$

Form A Cont.

(Q18) Do you feel there should be more health education topic areas discussed than just Q7 - Q11?

(Physical Fitness, Obesity Prevention, Nutrition, Illicit Drug Use, Human Sexuality)

Yes $-\mathrm{No}$ 
If You Answered Yes to the Last Question (Q18), Please Elaborate Which Topics You Believe Should Be Included In Health Education Curricula

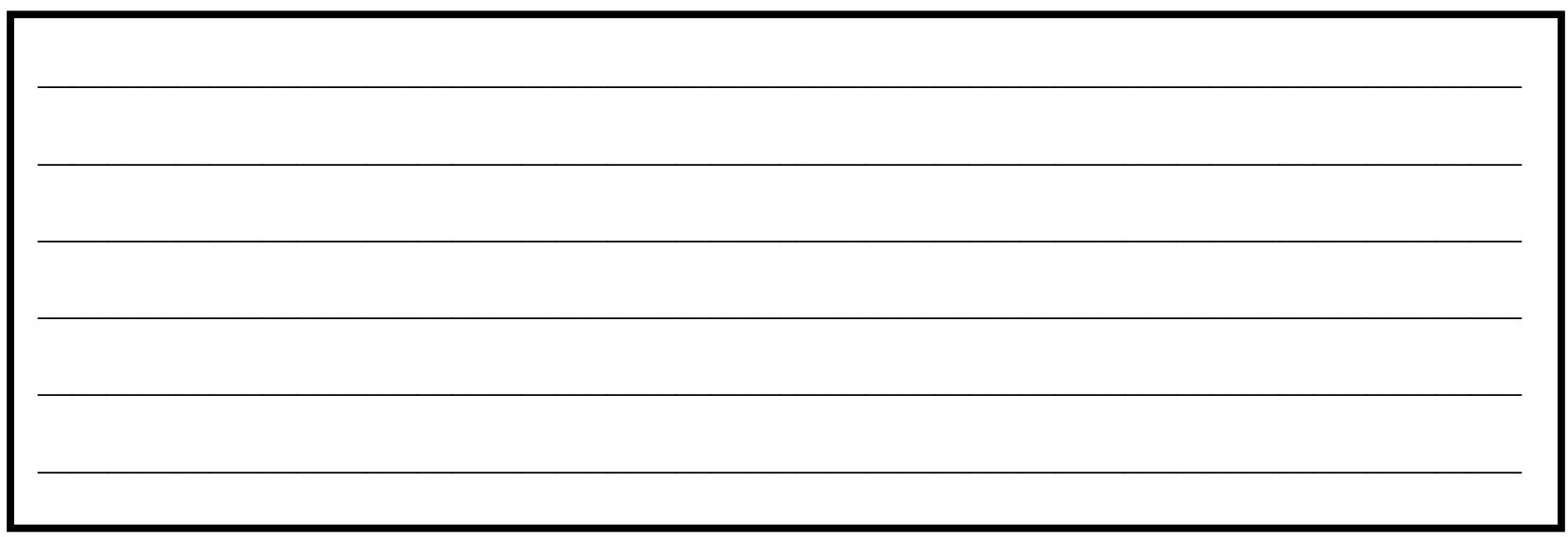

Thank you for completing this survey!

** If you would like a copy of this survey or would like to express any feelings regarding this survey please contact:

Form B.

Health Education Confidence Survey (HECS) Recent Graduate

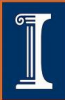

\section{University of Illinois at Urbana- Champaign}

\section{Directions:}

\section{Confidence Survey}

This survey is entirely optional. I would like your feedback on how well you believe your Kinesiology/Physical Education and/or Health Endorsement curriculum has prepared you for your work as a health educator. Please review and answer the following questions to the best of your ability. 
Form B Cont.

Please rate your agreement with the following statements about your Kinesiology \& Physical Education program and/or Health Endorsement coursework

on a scale of 1 to 5 with 1 being strongly disagree and 5 being strongly agree:

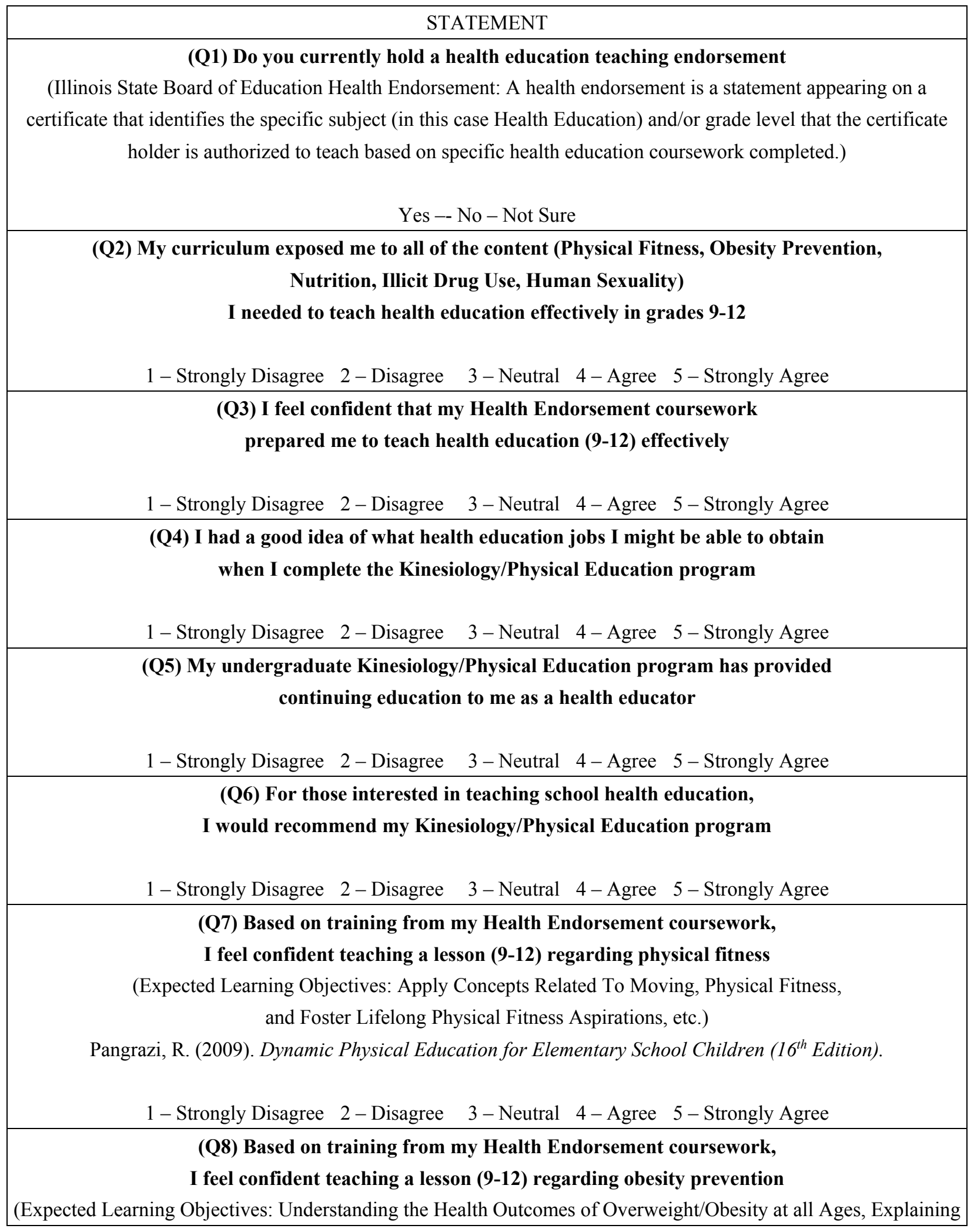




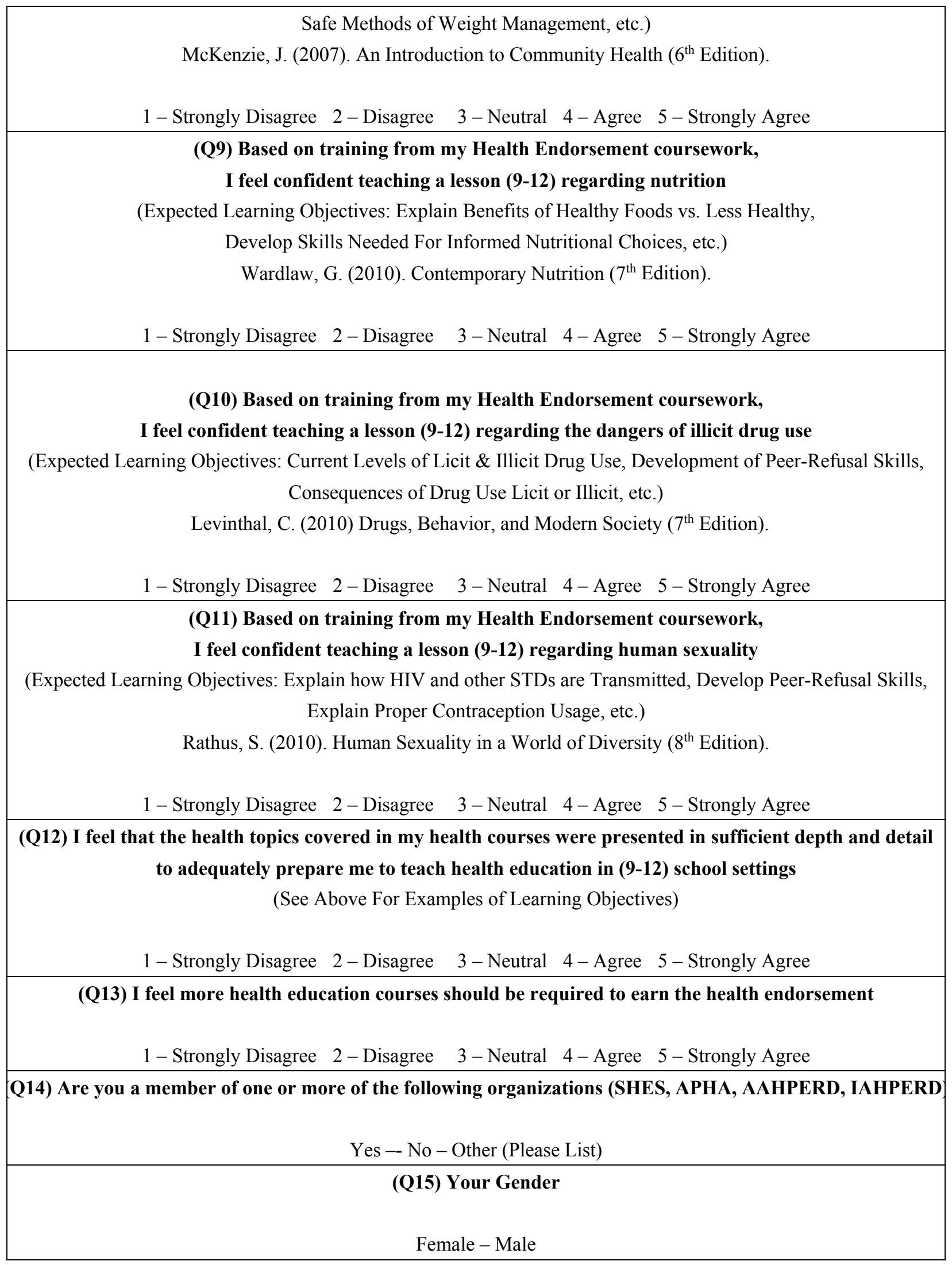


(Q16) As a Kinesiology/Physical Education major, my primary focus was in...

K-12 Teaching - Physical Education - Health Education - Biomechanics - Coaching/Administration - Undecided Other

(Q17) What year did you graduate

$2005-2006-2007-2008-2009-2010-2011$

(Q18) Does your current employer require you teach Abstinence-Only sexual education?

Yes - No - Uncertain

(Q19) Do you feel there should be more health education topic areas discussed than just Q7 - Q11?

(Physical Fitness, Obesity Prevention, Nutrition, Illicit Drug Use, Human Sexuality)

Yes - No

If You Answered Yes to the Last Question (Q18),

Please Elaborate Which Topics You Believe Should Be Included In Health Education Curricula

Thank you for completing this survey!

** If you would like a copy of this survey or would like to express any feelings regarding this survey please contact: 